\title{
Ценовой паритет калорийности
}

\section{Тимофей Шабанов}

Челябинский государственный университет, г. Челябинск, Россия

\section{Информация о статье}

Поступила в редакичию:

21.09.2020

Принята

к опубликованию:

30.11.2020

УДК 338.439

JEL Q18, Q17

\section{Ключевые слова:}

продовольственная безопасность, методология, ценовой паритет, калорийность продовольствия, цена калории

\section{Keywords:}

food security, methodology, price parity, calorie concentration of foods, calorie price

\begin{abstract}
Аннотация
$B$ чрезвычайной ситуации государственной самоизоляции актуализируется вопросы продовольственной безопасности - иенового паритета калорийности продуктов питания. В исследовании рассмотрена и подтверждена гипотеза о существовании взаимосвязи иены с калорийностью продовольствия как ценового паритета. На основе методов эконометрики и энергетического подхода, данных Росстат за 1998-2017 г2. определены цеены и калорийности по видам продовольствия. Выявлен линейный характер годового прироста цены калории при стабильном ценовом паритете. Установлены среднегодовые темпы прироста цены потреблённого продовольствия - 1,77 руб./Мкал к произведённому 0,38 руб./Мкал (отношение 4,66:1), средняя цена импортной калории - 1,24 USD/Мкал, экспортной 0,16 USD/Мкал (отношение 7,75:1). Импортозамещение как основное направление улучшения иенового паритета обеспечит продовольственную безопасность в чрезвычайной ситуации.
\end{abstract}

\section{Calorie Price Parity}

Timofei Shabanov

\section{Abstract}

In the emergency situation of the state self-isolation food security issues - caloric food price parity - are brought up to date. The level of food prices can be a kind of the regulator for planning, organizing and managing the optimal calorie intake by the population. The paper suggests the existence of a function between price and calorie content (number of calories); and the hypothesis on availability of the caloric food price parity was considered and tested. To study the hypothesis, the following objectives were developed and consistently solved: determining the prices and parity of calories produced and consumed; determination of prices and parities of exported and imported calories.

Based on the econometric methods and energy approach, as well as on the Rosstat data for the period of 1990-2017 and the Russian Customs data on food product balances and its prices, the wellknown calorie standards for food products, the hypothesis of the investigation was confirmed. The linear nature of the annual increase in the price of calories at the stable price parity was defined. It was found that the average annual growth rate of the consumed food price was 1.77 rubles/Mcal to the produced 0.38 rubles/Mcal (ratio 4.66: 1), the average price of the imported calories was 1.24 USD / Mcal and that of the exported calories was 0.16 USD / Mcal ( ratio 7.75: 1). Import substitution as the main trend for improving the price parity will ensure food security in an emergency situation. 


\section{Введение}

Продовольственная безопасность определяется энергетической (калорийностью) и общественной (денежным эквивалентом) ценностями продуктов питания. Калорийность (от лат. calor, «тепло») - расчётное количество тепловой энергии (измеряемое в калориях или джоулях), которое вырабатывается организмом человека или животных при усвоении (катаболизме) съеденных продуктов. Зависит от химического состава пищи (количества белков, жиров, углеводов и других веществ). Являясь энергетической характеристикой продовольствия, калорийность определяет резерв энергии, который необходим для жизнедеятельности и трансформации в физическую работу. Паритет (от лат. paritas «paвенство») - равенство взаимоотношений двух или более сторон по каким-либо параметрам. Ценовой паритет калорийности - равенство взаимоотношений (пропорциональность) цен за калорийность продовольствия. Улучшение ценового паритета калорийности - изменение взаимоотношений (пропорциональности) цен за калорийность для повышения продовольственной безопасности.

По данным исследования НИИ Питания РАМН [1], энергетический критерий оценивается по уровням потребления, - по возрастным группам, по физической нагрузке и т.д. Недостаток калорийности продовольствия приводит к недоеданию и, как следствие, снижению физической активности. Избыток калорийности может привести к перееданию и снижению активности жизнедеятельности из-за ожирения. Вследствие множества факторов (природно-климатических, демографических, медико-физиологических, трудовых и т.д.) сложно точно определить норму калорийности на душу населения как ориентир для долгосрочного развития. Для расчётов примем условно 2 Мкал как среднедушевую суточную потребность как минимальную гарантию продовольственной безопасности.

Перспективность использования калорийности как энергетического критерия оценки продовольственной безопасности объясняется простотой и доступностью для использования в предварительных оценках. Например, приняв среднедушевую суточную потребность в 2 Мкал (1000 ккал или 1000000 кал) в год (365 дней) потребуется 730 Мкал/чел. в год (0,730 млн ккал/чел. в год), а для популяции 147 млн россиян (прогноз Росстат на 2020 г.) необходимый годовой минимум калорийности для обеспечения продовольственной безопасности составит 107 млрд Мкал.

Энергетический подход по определению ценности продовольствия является междисциплинарным и рассматривается в таких дисциплинах как экономика, биохимия, биофизика, зоотехния и т.д. Преимущество энергетической оценки возможность калькуляции энергии различных видов. Например, для получения привеса в 1 кг мяса (животный продукт) требуется потратить кормовые единицы эквивалентно 5 кг зерна (растительный продукт). Для суточной жизнедеятельности человеку требуется энергии эквивалентно 1 кг мяса или 1 кг зерна (условно). Однако, животный продукт может иметь незаменимые вещества, для человеческого организма которые могут отсутствовать в растительном продукте. Поэтому следует разделять калории растительного происхождения и калории животного происхождения (в дальнейшем - растительная и животная калория, если вид происхождения не указан - калория).

Цена продовольствии может быть регулятором планирования, организации, управления питания популяции, как процесса оптимального потребления калорий (оптимум между недоеданием и перееданием). Например, если на внутреннем рынке наблюдается переизбыток калорий, то снижение экспортных цен повысит экспорт калорий. Таким образом, предположение о существовании 
взаимосвязи цены с калорийностью (количеством калорий) формирует гипотезу о наличии ценового паритета калорийности продовольствия.

Для проверки гипотезы сформированы и последовательно решены следующие задачи:

1) определение цен и паритета произведённых и потреблённых калорий;

2) определение цен и паритета экспортируемых и импортируемых калории.

\section{Методы исследования}

Калькулируя данные Росстата по количеству ресурсов и использованию мяса и мясопродуктов, молока и молокопродуктов, яиц и яйцепродуктов, зерна, овощей и бахчевых культур, картофеля , фруктов и ягод по Российской Федерации [2] за 1990-2017 гг., перемноженные на усреднённые нормативы калорийности (табл. 1) и разделенные на численность населения России [3], определим цену произведённой калории по годам (рис. 1).

Таблица 1

Калорийность продуктов

\begin{tabular}{|l|c|}
\hline \multicolumn{1}{|c|}{ Продукты } & Калорийность, ккал/100 г. \\
\hline Зерно и зерновые продукты & 295 \\
\hline Картофель & 77 \\
\hline Овощи и бахчевые культуры & 31 \\
\hline Фрукты и ягоды & 56 \\
\hline Масло растительное & 884 \\
\hline Мясо и мясопродукты & 275 \\
\hline Молоко и молочные продукты & 55 \\
\hline Яйца и яйцепродукты & 160 \\
\hline Сахар & 387 \\
\hline
\end{tabular}

Источник: составлено автором

Отметим, что растительная калория представлена зернопродуктами, овощами и бахчевыми культурами, картофелем, фруктами и ягодами, а животная калория - мясопродуктами, молокопродуктами, яйцепродуктами. В рассмотрении потребления имеется сахарно-жировая калория, которую представляют сахаропродукты и маслопродукты растительного происхождения, большей частью импортируемые на российский рынок.

Используя данные Росстат о среднедушевом потреблении основных продуктов питания по Российской Федерации [4], нормативы калорийности [5] (табл. 1), потребительские цены на отдельные виды товаров и услуг [6], получим значения цены калории потребления по видам (рис. 1).

Для определения динамики цены калорий по виду происхождения воль пользуемся регрессионным анализом и рассчитаем при помощи программы MS Excel коэффициенты линейных регрессий и определим их коэффициент достоверности $\mathrm{R}^{2}$ (Рис. 1). Практическое значение коэффициента линейной регрессии соответствует ежегодному темпу прироста показателя, а соотношение показателей коэффициентов демонстрирует уровень одного показателя над другим как ценовой паритет калорийности.

Используя данные таможенной статистики о стоимости импорта и экспорта продовольствия [7], рассчитанные данные по калорийности и весу импорта и экспорта, рассчитаем данные по цене калории и цене брутто (весу) продовольствия. Отметим, что под брутто понимаются те данные по весу (тоннажу), которые приводит Федеральная таможенная служба (далее - ФТС) в качестве данных о транспортной массе продуктов. Стоимость экспорта-импорта учитывается ФТС 
в долларах США. Путём деления полученной калорийности импорта и экспорта на вес, получим удельную калорийность импорта и экспорта продовольствия. Результаты представим Ошибка! Источник ссылки не найден..

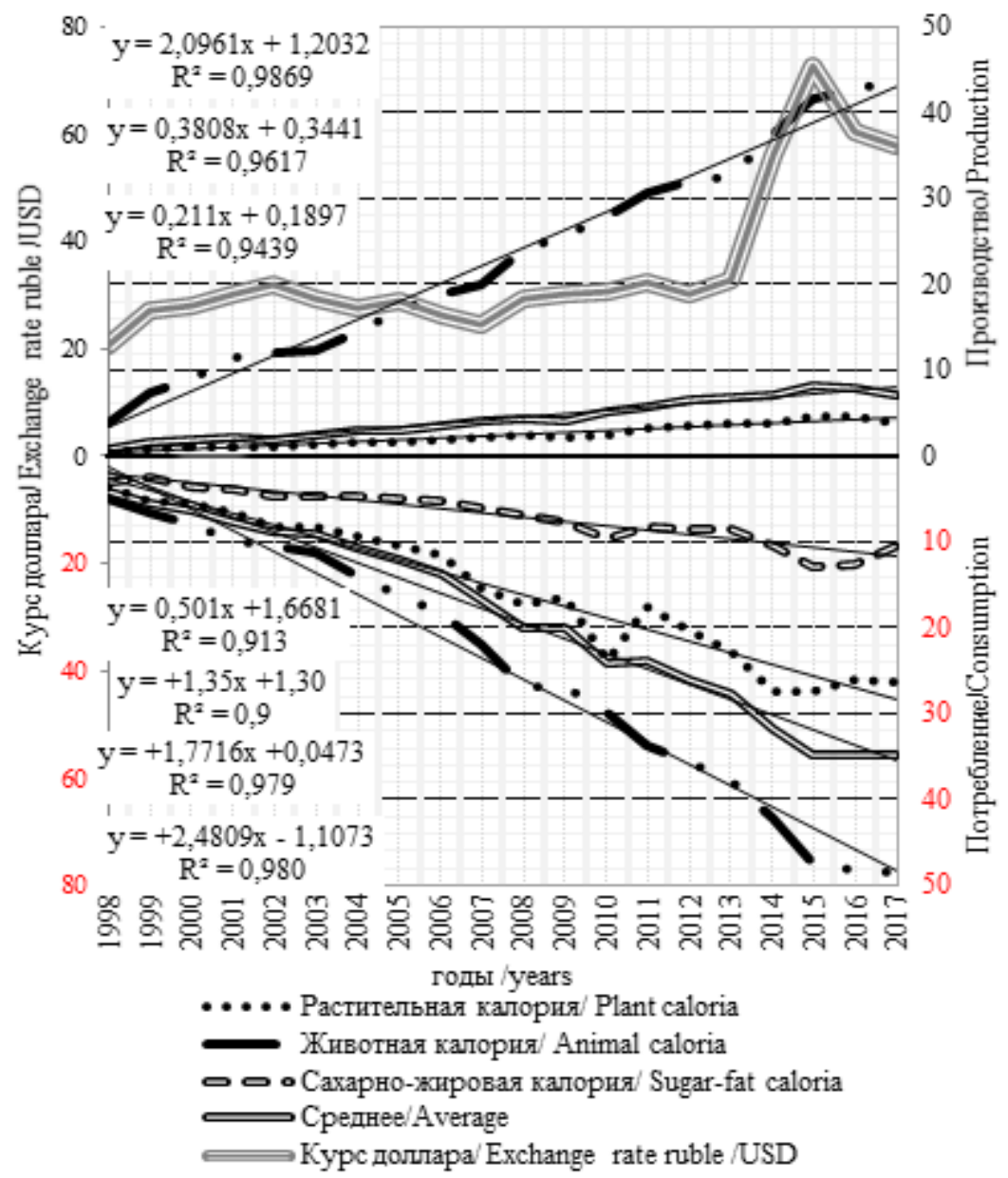

Источник: составлено автором

Рис. 1. Цена калории России, руб./ Мкал

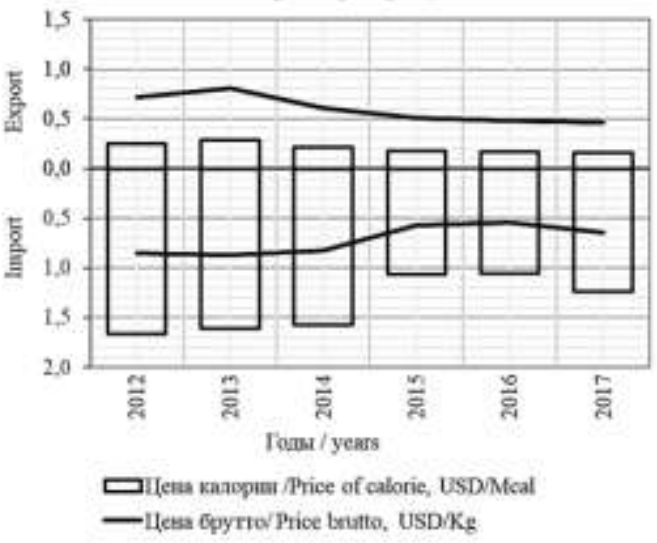

Puc. 2. Динамика цены импорт-экспортных калорий

в Российской Федерации на душу населения в год

Источник: составлено автором 


\section{Результаты}

Анализируя ценовой уровень и динамику продовольственной калории (Таблица 2и Ошибка! Источник ссылки не найден.), очевидно, что производство животной калории обходится в 11,36 раз дороже растительной, а темп прироста цены животной калории выше в 9,53 раз чем растительной.

Таблица 2

Цена продовольственной калории России

\begin{tabular}{|l|c|c|c|c|}
\hline \multirow{2}{*}{ Калория } & \multicolumn{2}{|c|}{ Произодство } & \multicolumn{2}{c|}{ Потребление } \\
\cline { 2 - 5 } & $\begin{array}{c}\text { Цена 2017 г., } \\
\text { руб/Мкал }\end{array}$ & $\begin{array}{c}\text { Темп прироста, } \\
\text { руб./Мкал }\end{array}$ & $\begin{array}{c}\text { Цена 20172, } \\
\text { руб./Мкал }\end{array}$ & $\begin{array}{c}\text { Темп прироста, } \\
\text { руб./Мкал }\end{array}$ \\
\hline В среднем & 6,97 & 0,38 & 34,76 & 1,77 \\
\hline Растительная & 3,85 & 0,21 & 26,40 & 1,34 \\
\hline Животная & 43,75 & 2,09 & 48,56 & 2,48 \\
\hline Сахарно-жировая & - & - & 10,31 & 0,50 \\
\hline
\end{tabular}

Источник: составлено автором

Ценность потребляемой животной калории выше цены растительной калории в 1,84 раз, а темп прироста цены животной калории выше 1,85 раз чем растительной, что в целом сопоставимо с абсолютными показателями. Сахарножировая калория имеет цену в 2,56 раз ниже чем растительная и в 4,7 раз - животной калории. Темп прироста цены растительной калории ниже в 2,68 раз темпа прироста растительной калории и 4,96 раз - животной калории. В общем, цена калории потреблённой в 4,99 раз выше, чем цена калории произведённой. Это указывает на то, что на каждых 5 руб. в цене потреблённой калории, 4 руб. приходится на оплату услуг сфер переработки, распределения и обмена. При этом темп прироста цены калории потреблённой в 4,65 раз выше, чем цена калории произведённой. Обратим внимание на то, что внутренний рублёвый рынок потребления и производства определен внутренними факторами, чем внешними (например, колебания доллара в 2014-2016 гг.).

Ценовой паритет калорийности - цена потреблённой калории соотносится с ценой произведённой калории как 34,76 руб./Мкал (2017 г.) к 6,97 руб./Мкал (2017 г.)- = 4,99:1. Если предположить, что для обеспечения продовольственной безопасности России требуется 107 млрд Мкал в год, то при ценах 2017 г. можно определить минимальный уровень расходов населения 107 млрд Мкал * 34,76 руб./Мкал = 3,7 трлн руб. в год, а валовый объем производства сельскохозяйственной продукции на уровне 107 млрд Мкал * 6,97 руб./Мкал = 0,75 трлн руб. в год.

Рассмотрим вопрос общественной ценности импортируемой и экспортируемой калорий (рис. 2). Очевидно, что при сопоставимых ценах 0,5 доллара за кг, цена за импортируемую калорию (1,24 доллара/Мкал - 2017 г.) в 7,75 раз выше, чем за экспортируемую. (0,16 доллара/Мкал - 2017 г.).

Ценовой паритет калорийности - цена импортной калории соотносится с ценой экспортной калории как 1,24 доллара/Мкал (2017 г.) к 0,16 доллара/Мкал (2017 г.)- = 7,75:1. Зная цену импортной и экспортной калорий, нетрудно просчитать минимальную стоимость продовольственного бюджета россиян при питании по ценам импорта и по ценам экспорта. Таким образом, для популяции 147 млн россиян (прогноз Росстат на 2020 г.) при необходимом годовом минимуме калорийности для обеспечения продовольственной безопасности в 107 млрд Мкал, продовольственный бюджет по цене на импорт 1,24 доллара/Мкал (2017 г.) составит 132,6 млрд долларов, а при цене экспорта 0,16 доллара/Мкал (2017 г.) - 17,1 млрд доллара, т.е. разница составит 115,5 млрд долларов. 


\section{Дискуссия и выводы}

Несмотря на простоту и доступность, описанный энергетический подход в оценке продовольственной калории имеет и ряд недостатков. Калорийность продуктов питания определяется множеством факторов: сортом и видом, технологией выращивания и хранения, свежестью, местом происхождения и т.д. Методика калькуляции и соизмерения Росстата, как и ошибки респондентов формируют погрешность данных. В этой связи вопрос определения погрешности и повышение точности представляет интерес для дальнейшего исследования.

Рассматривая полученные результаты о ценах калории и их паритете, констатируем о подтверждение выдвинутой ранее гипотезы о наличии и относительной стабильности ценового паритета калорийности продовольствия.

Исходя из вышеизложенного, можно сделать следующие выводы.

Динамика цен произведённой и потреблённой калории имеет линейный характер при стабильном ценовом паритете. Это указывает на сложившуюся ценовую структуру и наличие государственного регулирования (контроля) цен на продовольствие.

В условиях чрезвычайной ситуации, для обеспечения (сохранения калорийности) продовольственной безопасности в условиях ограничения (сокращения) производственных возможностей следует наращивать количество растительной калории за счёт сокращения производства животной калории.

Кроме того, в условиях чрезвычайной ситуации, замещение животной калории растительной и сахарно-жировой позволяет сократить в разы стоимость рациона населения. Однако отказ от потребления калорий животного происхождения может привести к необратимым физиологическим последствиям.

Среднегодовые темпы прироста цены потреблённого продовольствия 1,77 руб./Мкал к произведённому 0,38 руб./Мкал (отношение 4,66:1), средняя цена импортной калории 1,24 USD/Мкал, экспортной 0,16 USD/Мкал (отношение 7,75:1). При этих ценовых соотношениях перспективное по направление повышению продовольственной безопасности видится в сокращении экспорта растительной калории и перенаправлении его в развитии производства животной калории, т.е. импортозамещении. Таким образом, ограничивая дешёвый экспорт растительной калории, возможно предоставить потребителю недорогую (в сравнении с импортной) животную калорию и формировать резерв растительной калории для условий чрезвычайной ситуации.

\section{Список источников / References}

1. МР 2.3.1.2432-08. 2.3.1. Рациональное питание. Нормы физиологических потребностей в энергии и пищевых веществах для различных групп населения Российской Федерации. Методические рекомендации" (утв. Роспотребнадзором 18.12.2008.

2. Балансы продовольственных ресурсов // http://old.gks.ru/wps/wcm/connect/rosstat_main/rosstat/ru/statistics/enterprise/economy (accessed 15.01.2020).

3. Численность населения// http://old.gks.ru/wps/wcm/connect/ rosstat_main/rosstat/ru/statistics/ population/demography/\# (accessed 15.01.2020).

4. Потребление основных продуктов питания по Российской Федерации// http://old.gks.ru/wps/wcm/connect/rosstat_main/rosstat/ru/statistics/enterprise/economy/\# (accessed 15.01.2020).

5. Скурихин И.М., Тутельян В.А. Таблицы химического состава калорийности российских продуктов питания. Москва, ДеЛи принт, 2007. 275 с. 
6. Средние потребительские цены на отдельные виды товаров и услуг//http://old.gks.ru/wps/ wcm/connect/rosstat_main/rosstat/ru/statistics/tariffs/\# (accessed 15.01.2020).

7. Внешняя торговля Российской Федерации (по данным таможенной статистики)// http://old.gks.ru/wps/wcm/connect/rosstat_main/rosstat/ru/statistics/ftrade/\# (accessed 15.01.2020).

\section{Сведение об авторе / About author}

Шабанов Тимофей Юрьевич, кандидат экономических наук, доцент кафедры «Вычислительная механика и информационные технологии», Челябинский государственный университет. 454001 Россия, Челябинск, ул. Братьев Кашириных, 129, каб. 418. E-mail: shabanov@csu.ru

Timofei Yu. Shabanov, Candidate of Economic Sciences, Associate Professor of the Department of Computational Mechanics and Information Technologies, Chelyabinsk State University. Office 418, Kashirin brother's str. Chelyabinsk, Russia 454001.E-mail: shabanov@csu.ru 